\title{
An Empirical Study of the Relationship between Transportation and Economic Growth in Xinjiang Province
}

\author{
Jinbo Wang \\ School of Economic \& Trade, Shihezi University \\ Shihezi 832003, China \\ E-mail: shzdx@163.com
}

\begin{abstract}
Along with the development of socialist market economy and the improvement of transportation facilities, the driving effect of transportation industry on economic growth tends to be more significant. The transportation industry is the lifeline of national economic growth and the backbone of material activities and community communication, signalizing the development of national economy. Highly- developed transportation industry has important strategic meanings for a country's economic prosperity, cultural development, strong defense, and people's well-off life. Based on the grey system theory and econometrics, this paper analyzes the contributing effect of the transportation industry on Xinjiang's regional economic growth, and studies the relationship between indexes of Xinjiang's transportation industry and economic growth, supplying references for researching Xinjiang's regional economic development.
\end{abstract}

Keywords: Transportation industry, Economic growth, Correlation, Grey system

\section{The relationship between transportation industry and economic growth}

Transportation is a basic industry for national economic development, which associates with other industries interdependently and closely. On one hand, the development of transportation industry is an important precondition for maintaining the fast growth of national economy, which exerts a "pulling effect" on economic development. On the other hand, the fast development national economy needs developed transportation industry as the infrastructure. Economic development exerts a "pushing effect" on transportation industry. Therefore, for a long period, the research on the relationship between transportation industry and economic growth is always the focus of domestic and foreign scholars in the field.

Many foreign scholars have made theoretical and empirical analyses on this issue. At the first half of $19^{\text {th }}$ century, Freidrich Liszt, as the founder of historical school of Germany bourgeois economists, in perspective of developing capitalist industry and commerce, advanced the national productivity theory that focuses on transportation studies. In his opinion, to develop the transportation industry can drive the prosperity and development of economy. Post and transportation are the source of productivity. William Petty took Holland as an example and concluded that the specialization of transportation tools improves the effect of wealth by decreasing transportation fees and saving labors. The French scholar Thunen, a theoretical forerunner of modern western production location and industry distribution, regarded the production cost, transportation fee, and price as the decisive factors of production allocation. In his eyes, the primary principle of production allocation is to decrease the production cost and transportation fee and realizes the minimum price. Adam Smith, an economist, thought: (1) Transportation is vital for national economic development. "The development of one country's commerce completely relies on powerful public facilities, including roads, bridges, canals, and ports. (2) "The development of infrastructure should be in accordance with the economic development. ......". Besides, in his book An Inquiry into the Nature and Causes of the Wealth on Nations, he discussed the effects of transportation on labor division and market development. He thought that the economic efficiency origins from labor division, but the labor division is restricted by market scope and transportation. The improvement of transportation conditions can not only decrease the transportation fee but also explore a wider market. As for the relationship between transportation and market supply and demand, Marx drew a penetrating conclusion that: "The development of transportation tools can shorten the spatial and time distance from production to market, change the commodities' spatial and time relative state, and enlarge the supply and demand of commodity market."

Some domestic scholars also analyzed the relationship between transportation industry and economic growth. In 2006, Liang Yu in his "An analysis of highway traffic on regional economy" analyzed the pushing effect of transportation industry on resources allocation in regional economic operation, starting from the essential issues of economy. He pointed out that the transportation industry is the lifeline of national economy, and developed transportation industry is meaningful for the national or regional economy, especially for industry allocation, industry structure optimization, and 
regional trade development. In 2007, Wei Xu and Minsheng Huang in their "Quantitative analysis of relationship between transportation and economic development in Fujian" made a correlation analysis of the relationship between Fujian transportation and national economic development by correlation coefficient and grey comprehensive correlation, and concluded that there is a high correlation between Fujian transportation and Fujian economic development. Besides, by a grey dynamic model and transportation elastic coefficient, they analyzed the adaptation of Fujian transportation and Fujian economic development, concluded the practical conditions of Fujian transportation at present, and advanced relevant policy suggestions.

\section{Set a correlation model}

Indexes for national economic growth are Gross Domestic Product (GDP), Gross National Product (GNP), total product of society, industrial and agricultural product, and household consumption. Indexes for transportation industry include freight volume, freight turnover, passenger volume, passenger turnover, length of railway, length of highway, and total mileage of freshwater shipping. According to the relationship between Xinjiang transportation and Xinjiang regional economic growth, and the data from Xinjiang Statistical Yearbook, we mainly take Xinjiang gross product

million Yuan), household consumption $y_{2}$ (Yuan per capita), freight volume $x_{1}\left(10,000\right.$ ton), freight turnover $x_{2}$ (100 million tons kilometer), passenger volume $x_{3}\left(10,000\right.$ people), passenger volume $x_{4}$ (100 million tons kilometer) as indexes for quantitative model analysis.

\subsection{Correlation coefficient matrix}

Suppose $_{x_{1}}, x_{2}, \ldots \ldots, x_{m}$ as the correlated factor indexes. After observing these factors for $\mathrm{n}$ times, we get the sample data $x_{i}(k)(k=1,2, \ldots, n)$. Then, the matrix is:

$$
R=\left[\begin{array}{cccc}
r_{11} & r_{12} & \cdots & r_{1 m} \\
r_{21} & r_{22} & \cdots & r_{2 m} \\
\cdots & \cdots & \cdots & \cdots \\
r_{m 1} & r_{m 2} & \cdots & r_{m m}
\end{array}\right]
$$

Here, the correlation efficient $\boldsymbol{r}_{i j}=\frac{\sum_{k=1}^{n}\left(x_{i}(k)-x_{i}\right)\left(x_{j}(k)-x_{j}\right)}{\sqrt{\sum_{k=1}^{n}\left(x_{i}(k)-\overline{x_{i}}\right) \sum_{k=1}^{n}\left(x_{j}(k)-x_{j}\right)}}, x_{i}=\frac{1}{n} \sum_{k=1}^{n} x_{i}(k)$

$0 \leq \boldsymbol{r}_{i j} \leq 1$, it reflects the correlation of $x_{i}$ and $x_{j}$. The more $r_{i j}$ is close to 1 , the stronger the correlation between $x_{i}$ and $x_{j}$ is. As $r_{i j}$ is close to 0 , there is no correlation between $x_{i}$ and $x_{j}$. According to statistical data of Xinjiang from 1993 to 2007, we get the matrix of Xinjiang gross product $y_{1}$, household consumption $y_{2}$, freight volume $x_{1}$, freight turnover $x_{2}$, passenger volume $x_{3}$, and passenger volume $x_{4}$ as follow. 


$$
\begin{aligned}
& R_{1}=\left[\begin{array}{cccccc}
1 & 0.981546 & 0.996654 & 0.992757 & 0.994644 \\
& 1 & 0.986275 & 0.991092 & 0.983126 \\
& & 1 & 0.995360 & 0.997179 \\
& & & 1 & 0.996328 \\
& & & & 1
\end{array}\right] \\
& R_{2}=\left[\begin{array}{cccccc}
1 & 0.990705 & 0.982890 & 0.982887 & 0.978929 \\
& 1 & 0.986575 & 0.991092 & 0.983126 \\
& & 1 & 0.995360 & 0.997179 \\
& & & 1 & 0.996328 \\
& & & & & 1
\end{array}\right]
\end{aligned}
$$

\subsection{Correlation analysis}

From the correlation coefficient matrix, we notice that the correlation coefficients of $R_{1}$ and $R_{2}$ are larger than 0.95. It means the development of Xinjiang gross product $y_{1}$ and household consumption $y_{2}$ has a close relationship with the development of freight volume $x_{1}$, freight turnover $x_{2}$, passenger volume $x_{3}$, and passenger volume $x_{4}$. We can conclude that the development of Xinjiang transportation industry contributes a lot to Xinjiang regional economic development. In perspective of numbers, the correlation coefficient of freight turnover and Xinjiang gross product is 0.996654 , larger than the correlation coefficient of freight volume, passenger volume, and passenger turnover. It indicates that the freight turnover has more significant effect on Xinjiang gross product. From the correlation coefficient matrix $R_{2}$, we notice that the correlation coefficient of freight volume and household consumption is 0.990705 , which means the freight volume has more significant effect on household consumption comparing with other indexes.

\section{Multi-dimensional grey dynamic model}

3.1 A brief introduction of the model

Suppose $X_{1}^{(0)}=\left(x_{1}^{(0)}(1), x_{1}^{(0)}(2), \ldots . ., x_{1}^{0}(n)\right)$ is the system's characteristics data sequence, while,

$X_{2}^{(0)}=\left(x_{2}^{(0)}(1), x_{2}^{(0)}(2), \ldots \ldots, x_{2}^{0}(n)\right)$

$X_{N}^{(0)}=\left(x_{N}^{(0)}(1), x_{N}^{(0)}(2), \ldots . ., x_{N}^{0}(n)\right)$

is the system's correlated factor sequence. $\quad X_{i}^{(1)}$ is $\quad X_{i}^{(0)}$ 's first-order accumulative sequence $(1-\mathrm{AOG})(\mathrm{i}=1,2, \ldots \ldots \mathrm{N})$. $Z_{1}^{(1)}$ is $X_{1}^{(1)}$ 's generated mean sequence of consecutive neighbors. Then, $x_{1}^{(0)}(k)+a_{Z_{1}}^{(0)}(k)=\sum_{i=2}^{n} b_{i} x_{i}^{(1)}(k)$ is GM $(1, \mathrm{~N})$ model. In this model, $a$ is the system development coefficient, $b_{i}$, the system driving system, namely the coordinative development coefficient, and $\hat{a}=\left[a, b_{2}, \ldots b_{N}\right]^{T}$, the parameter sequence.

If ${ }_{B}=\left[\begin{array}{cccc}-z_{1}^{(1)}(2) & x_{2}^{(1)}(2) & \cdots & x_{N}^{(1)}(2) \\ -z_{1}^{(1)}(3) & x_{2}^{(1)}(3) & \cdots & x_{N}^{(1)}(3) \\ \cdots & \cdots & \cdots & \cdots \\ -z_{1}^{(1)}(n) & x_{2}^{(1)}(n) & \cdots & x_{N}^{(1)}(n)\end{array}\right], Y=\left[\begin{array}{c}x_{1}^{(0)}(2) \\ x_{1}^{(0)}(3) \\ \cdots \\ x_{1}^{(0)}(n)\end{array}\right]$, then the parameter sequence $\hat{a}=\left[a, b_{2}, \ldots b_{N}\right]^{T}$,s least square satisfies $\hat{a}=\left(B^{T} B\right)^{-1} B^{T} Y$. Suppose $\hat{a}=\left[a, b_{2}, \ldots b_{N}\right]^{T}$, then $\frac{d x_{1}^{(1)}}{d t}+a x_{1}^{(1)}=b_{2} x_{2}^{(1)}+b_{3} x_{3}^{(1)}+\ldots .+b_{N} x_{N}^{(1)}$ is 
$x_{1}^{(0)}(k)+a_{Z_{1}^{(0)}}(k)=\sum_{i=2}^{n} b_{i} x_{i}^{(1)}(k)$ 's shadow equation.

Here as we use the $\mathrm{N}$ dimensional system model setting theory to study the coordination relationship between Xinjiang transportation and Xinjiang regional economic growth, we mainly make quantitative analysis of the system development coefficient $a$ and the driving coefficient $b_{i}$, and $x_{i}^{(1)}(k)$ in the model. If $a$ is smaller than 0 , the system has certain development competence. If $a$ is larger than 0 , the system has no development competence. According to the statistical data of Xinjiang gross product $y_{1}$ and household consumption $y_{2}$ has a close relationship with the development of freight volume $x_{1}$, freight turnover $x_{2}$, passenger volume $x_{3}$, and passenger volume $x_{4}$ from 1993 to 2007, we calculate GM $(1,5)$.

$$
\begin{aligned}
& \frac{d y_{1}^{(1)}}{d t}-0.9283 y_{1}^{(1)}=1.10032 x_{1}^{(1)}+0.93203 x_{2}^{(1)}+0.54311 x_{3}^{(1)}+0.34002 x_{4}^{(1)} \\
& \frac{d y_{2}^{(1)}}{d t}-0.86025 y_{1}^{(1)}=0.92016 x_{1}^{(1)}+0.41035 x_{2}^{(1)}+0.01032 x_{3}^{(1)}+0.45120 x_{4}^{(1)}
\end{aligned}
$$

Apparently, $a$ is smaller than 0 , it means the system has certain development competence. Therefore, the development of transportation industry has a positive promoting effect on economic growth. Besides, the coordinative development coefficient (the driving coefficient) is larger than 0 , which means in Xinjiang the freight volume, freight turnover, passenger volume, and passenger turnover develop in coordination and the transportation internal component factors are reasonable. The coordinative development of transportation internal component factors exerts a significant pushing effect on Xinjiang regional economic growth.

\subsection{Grey correlation analysis}

The essence of grey correlation analysis is to judge the relationship by the similarities of sequences' curves. The closer the curve is, the more significant the correlation of relevant sequences is. By means of grey correlation analysis, we can identify what factors exert more effects on the system and what less effects on the system, what serves as proofs for us finding the relationship between Xinjiang transportation indexes and Xinjiang regional economic growth influencing factors. According to the statistical data of Xinjiang gross product $y_{1}$ and household consumption $y_{2}$ has a close relationship with the development of freight volume $x_{1}$, freight turnover $x_{2}$, passenger volume $x_{3}$, and passenger volume $x_{4}$ from 1993 to 2007, we gets the grey correlation table (Table 1) as follow ( $\boldsymbol{r}_{\mathrm{i}}$ is the grey correlation degree).

According to this table, the contribution of freight turnover to Xinjiang gross product is the largest and that of freight volume to Xinjiang household consumption is the largest, what is in accordance with the conclusion drawn by us in the correlation model analysis. It is determined by Xinjiang's location. Xinjiang locates in western China. Most materials are chiefly imported from the inland. The development of Xinjiang transportation drives the regional trade between Xinjiang and the inland to a great degree, satisfying Xinjiang people's increasing needs for materials and cultures, improving Xinjiang people's living consumption level, and promoting Xinjiang's regional economic development.

\section{Conclusion and suggestion}

From the empirical relationship between Xinjiang transportation industry and Xinjiang economic growth, we can conclude that there is a bilateral interactive relationship. Only when there is effective transportation system, can it realize regional development and associate all national economic branches together and improve an area's regional economic competence. The transportation net can promote the urbanization process, reduce the gap between rich and poor, and increase regional employment. According to general laws of economy history development, the development of transportation industry can bring about a series of chain effect on the development of related industries. It can promote the optimization and upgrade of industrial structure, help to supply a favorable external environment for regional economic development, and make enterprises generate external economic benefit. Besides, transportation industry shows its irreplaceable effects on promoting Xinjiang's reasonable industry allocation, decreasing wastes of resources caused by unreasonable industry allocation, reducing market transition costs and information asymmetry, and absorbing foreign investments. Finally, it can promote the whole economic industrialization process and drive the economic development.

This paper analyzes the development of Xinjiang transportation industry from a macro aspect. In order to supply useful references for Xinjiang regional economic development, the author advances several suggestions as follow. 
(1) Improve the modernization level by depending on scientific and technological progresses. Considering the fact that the transportation is a capital and technology intensive industry, we can promote the transportation scientific and technological fruits actively, popularize new materials, new crafts, new technologies, and new methods, and speed up the transform from scientific and technological fruits to practical productivity. Besides, along with the coming of knowledge economy, information has already become a strategic resource and a unique production factor for economic development. To accelerate the construction process of transportation information is a long-term and urgent task for promoting the sustainable, fast, and healthy development of transportation industry. At present, Xinjiang's transportation industry lags behind in fields of information resource development, application, and share. Lots of information is coming from manual labors. Therefore, we should improve the scientific and technological level, emphasize on talent cultivation and employee quality improvement, creating a favorable condition for transportation industry pushing the development of Xinjiang regional economy.

(2) Continue the reform of transportation management system. We can establish the responsibilities of the central government and the local government and set up internal and external supervision institutions. Besides, we can introduce foreign latest transportation management system, legalizing the transportation management.

(3) Constitute regional difference strategy for transportation development. After completely understanding and mastering the relationship between regional transportation and regional economic development, by developing transportation infrastructure differently, we can achieve an effective match between transportation development and regional economic activity, thoroughly exerting the positive effect of transportation industry on regional economic operation, and finally realizing the optimization of transportation industry and regional economic development.

(4) Promote the marketization process of transportation and imperfect the transportation market system. Gradually perfect the legal system, regulate the transportation construction and operation, and build up scientific and reasonable "market entrance" standards and requirements. Take the railway as a breakthrough, break the industrial monopoly and regional restriction, further open the transportation market, decrease the entrance and quit standards, and drive the formation and development of unified transportation market. Perfect the transportation's pricing mechanism that is mainly based on the market supply and demand, and affected by the government, applying the classified guidance and management to transportation prices.

\section{References}

Deng, Julong. (2002). Basis for Grey Theory. Wuhuan: Huazhong University of Science \& Technology Press.

Liu, Sifeng., Dang, Yaoguo \& Fang, Zhigeng. (2004). Grey System Theory and the Application. Beijing: Science Press.

Wang, Chuanxu. (2004). Quantitative study of transportation's contribution to national economy growth. China Journal of Highway and Transportation. No.1.

Zhao, Jian \& Yang, Tie. (2003). On the relationship between the transportation industry and economic growth. Journal of Transportation Systems Engineering and Information Technology. No.3(2).

Table 1.

\begin{tabular}{|c|c|c|c|c|c|}
\hline & $r_{1}$ & $r_{2}$ & $r_{3}$ & $r_{4}$ & Order \\
\hline$y_{1}$ & 0.507359 & 0.620408 & 0.477927 & 0.551378 & $r_{2}>r_{4}>r_{1}>r_{3}$ \\
\hline$y_{2}$ & 0.585451 & 0.557232 & 0.575624 & 0.56183 & $r_{1}>r_{3}>r_{4}>r_{2}$ \\
\hline
\end{tabular}

